\title{
POSSIBILITIES OF COMBINED SURGICAL TREATMENT OF LUNG TUMOURS AND HEART DISEASES
}

\author{
Petr Habal ${ }^{1}$, Jiří Šimek, ${ }^{1}$ Vladimír Lonský ${ }^{1}$, Josef Novotny ${ }^{2}$ \\ Charles University in Prague, Faculty of Medicine and University Hospital in Hradec Králové: Department of Cardiosurgery; \\ Department of Radiology ${ }^{2}$
}

Summary: The purpose of the study was a retrospective evaluation of the outcome of surgical therapy of lung cancer in patients where there was concomitant cardiac disease and who underwent a cardiac operation either because of ischemic heart disease or because of valvular disease. These patients were operated on at various time intervals (two to ten months) after their cardiac operation. Some patients had their lung cancer surgery after the cardiac operation because of the high risk of possible cardiac postoperative complications; in one patient the lung operation preceded the cardiac one.

Key words: Lung resection; Cardiac operation; Simultaneous operation; Cardiopulmonary bypass

\section{Introduction}

At the beginning of the $19^{\text {th }}$ century, lung cancer was a little known disease. Nowadays it is one of the most frequent causes of death out of all cancer diseases. The incidence of lung cancer has been increasing especially over the last 40 years and is virtually the same on all continents. The increase of malignant growth becomes statistically significant in the $4^{\text {th }}$ decade, but the highest incidence in the population is reached in the $6^{\text {th }}$ decade. In men it is about four times higher then in women. In the last 30 years the incidence of lung cancer in women has grown, while in men it remained static (18).

The most significant risk factor in lung cancer development is definitely cigarette smoking (7). The dependence of the incidence of lung cancer on cigarette smoking was proved by Fingerland in the early 1970's. There is a direct correlation between the number of inhaled cigarettes and tumour incidence with 500000 and more inhaled cigarettes the incidence of lung cancer risk raises by 25 times compared with non-smokers (12).

The surgical therapy of lung cancer is still the most radical of the therapeutic methods. The 5-year survival rate in patients operated on is about $32 \%$. It is also dependant on histological type of tumour. In the non-operated patients it falls to about $9-10 \%(25)$. That is why we try to offer surgical therapy to the largest possible amount of patients. Ever more high-risk patients with a number of associated diseases are indicated for lung operation. Among them there are the patients with cardiac disease and patients with a previous history of cardiac surgery.
The timing of surgical therapy in patients with both known lung cancer and cardiac disease has recently been a topical question $(9,16,17,23)$. The number of such affected patients is increasing because both diseases have some common risk factors. In our department we use the following algorithm of therapy.

In patients with known cancer disease (usually histologically confirmed by a transthoracal puncture) we carry out the cardiac operation initially (most often a revascularization) and after we proceed to resection of the lung cancer. Our main concern is to reduce the risk of complications following the lung resection which in a non treated heart disease would prove too high. The objective of our paper was to evaluate the results of the surgical therapy in patients with both lung cancer and cardiac disease, in whom we first carried out a cardiac operation, and consecutively, at various time intervals, a lung resection.

\section{Patients and Method}

In the period from January 2000 to December 2004, the team at the Cardiosurgical department of Charles University Faculty Hospital in Hradec Králové operated on $\mathbf{1 1}$ $(2,6 \%)$ patients from the total amount of 431 patients with lung cancer. These patients had simultaneously cardiac disease and were referred for surgical therapy. Seven patients had an affected coronary stream and thus were indicated for a revascularizational cardiac operation; 2 patients had an indication for a replacement of the aortal valve, and $\mathbf{2}$ for a replacement of the mitral valve because of a heart defect. By comparing the TNM classification of the staging 
before the lung resection with the pathological classification pTNM0 after the lung resection we tried to answer the question of the proper timing of both cardiac and lung operations. The distribution of our patients according to the TNM classification (1977 version) $(19,20)$ is shown in table 3 . We have retrospectively analysed a group of patients consisting of 7 men aged 56-78 (mean 67 years) and 4 women aged 58-70 (mean 64 years). Tab. 1. This set was divided into three groups regardless of the gender.

1) In the first group there were 2 women aged 58 and 70 , in whom we first carried out a left lower lobectomy because of carcinoid, and a right upper lobectomy because of an adenocarcinoma with a lymphadenectomy of accessible mediastinal nodes. The malignant growth was not proved in the lymphatic nodes. 38 months after the lung operation in the younger female, and 36 months in the elder one, the replacement of the aortal valve by a artificial valve prosthesis was carried out. In these patients the aortic stenosis had been diagnosed previously because of a congenitally bicuspid valve. Heart defects in both patients did not fulfil all the diagnostic criteria for a cardiac operation referral in the time when the lung cancer was diagnosed and operated on.

2) The second group was formed by 5 patients, 4 men and 1 female, in whom the lung cancer was known before the cardiac operation. The lung resection was postponed because of the severe finding in the coronary stream, which could complicate the postoperative period. The revascularization of the myocardium was therefore carried out first. The first patient was a 61-year-old male. We used cardiopulmonary bypass and carried out the revascularization by triple coronary artery bypass grafting (CABG). After 2 months of convalescence we approached the left upper lobectomy, because of the known adenocarcinoma which had been proved by transthoracic biopsy.

During the operation a mediastinal lymphadenectomy of 4 regional mediastinal nodes was carried out, namely hilar, lower paratracheal and upper paratracheal ones. An invasive adenocarcinoma with a pathological classification pT2N2Mx was proved histologically in all 4 nodes, although the tumour had been pre-operatively assessed as T2N0M0. This happened before the cardiopulmonary bypass operation. The zone of the resection stump was without any sign of tumorous invasion. Tab. 3.

The second patient in the group was a 63-year-old female, in whom revascularization of the left anterior descending (LAD) was carried out using the left mammary artery by mini-invasive access from the left anterior small thoracotomy (LAST). After 4 months we carried out a segmental resection of the $6^{\text {th }}$ segment of the left lower lobe because of the squamous cell carcinoma verified by a puncture. We removed 3 nodes in the mediastinum, in which the tumorous growth was not histologically proved.

The TNM classification, again prior to the cardiac operation, was T1N0M0, and the pathological classification after the lung operation was pT1N0M0. Tab. 3 .

The third patient in this group was a 56-year-old male, in whom the lung tumour, verified by a puncture with a histological finding of squamous cell carcinoma in the right lower lobe, was known before the cardiac operation.

Because of the serious coronarographic finding we at

Tab. 1: Set of patients with surgical details.

\begin{tabular}{|c|c|c|c|c|c|}
\hline Age & Sex & CS procedure & Lung procedure & Months & NYHA \\
\hline 56 & male & CABG $-2 \mathrm{x}$ & DLL & +8 & I. \\
\hline 58 & female & AVR & LLL & -38 & II. \\
\hline 61 & male & CABG $-3 x$ & LUL & +2 & II. \\
\hline 63 & female & LIMA-LAD & LSgR6 & +4 & II. \\
\hline 63 & male & MVR & RSgR6 & 0 & III. \\
\hline 66 & male & CABG $-2 x$ & Enucleation & +10 & II. \\
\hline 66 & female & MVR $*$ & RsgR6 & 0 & III. \\
\hline 69 & male & CABG $-2 x$ & Enucleation & II. \\
\hline 70 & female & AVR & RUL & -36 & II. \\
\hline 75 & male & CABG $-2 x$ & Extirpation & 0 & II. \\
\hline 78 & male & CABG-2x & RLL & $+2 /+2$ & III. \\
\hline
\end{tabular}

\section{Legend:}

LIMA-LAD - revascularization of the left anterior descending the left mammary artery

CABGx - revascularization using - $\mathrm{x}$ - arterial and venous grafts

Ao - aortal replacement by mechanic prosthesis

Mi - mitral replacement by mechanic prosthesis

Mi* - mitral replacement by mechanic prosthesis from right thoracotomy

LUL - left upper lobectomy

LLL - left lower lobectomy
RUL - right upper lobectomy

RLL - right lower lobectomy

LSgR6 - left segmental resection

RSgR6 - right segmental resection

Months - + - time from the cardiac to the lung operation in case of primarily known tumour

- time from the lung to the cardiac operation

$+2 /+2$ - time from the cardiac operation to the chemotherapy/time from the chemotherapy to the lung resection 
first carried out a revascularization of 2 coronary arteries (LAD, RC) using cardiopulmonary bypass.

The patient was referred as a candidate for lung operation, but because of personal reasons he reported only after 8 months. We carried out a standard right lower lobectomy and lymphadenectomy of the ipsilateral nodes. Histological staging was pT2N1M0, and the final histology confirmed the original diagnosis of a squamous cell tumour. Tab. 3 .

The next patient from this group was a 78-year-old male with a tumour of the right lower lobe, which was incidentally detected during the preoperative examination. The tumour was histologically confirmed as adenocarcinoma and classified according to the TNM classification as T2N2M0 stage. The patient underwent a revascularization of the myocardium by double aorto-coronary bypass. After 2 months he underwent neoadjuvant chemotherapy and after the re-staging his condition was assessed as T2N1M0 according to CT. He was therefore offered a lung operation. After 2 months of chemotherapy we carried out a right lower lobectomy with a lymphadenectomy. The histological finding again confirmed an adenocarcinoma, and there was no proved tumorous growth in the resected nodes.

The last patient in this group was a 66-year-old male, in whom we planned double $\mathrm{CABG}$ using cardiopulmonary bypass (CPB). Before that we intended to resect tumour in the right upper lobe. According to a histological verification it was a chondrohamartoma. We did not succeed in removing the deposit from median sternotomy.

Because of the known benign character of the tumour we decided to carry out the revascularization initially and to remove the tumour from the lung parenchyma afterwards. Because of unknown reasons the patient did not attend for his enucleation surgery for 10 months. Tab. 3 .

3) The third group was formed by 4 patients, 3 men aged 63 to 75 years, and 1 female 66 years old.

In one patient a round shadow in the left upper lung field, which was placed peripherally, was discovered during the screening X-ray examination prior to the planned revascularization. After taking the left mammary artery we enucleated a hard lobular structure prior to the administration of heparin. The result of per operative biopsy confirmed the suspicion of chondrohamartoma.

Tab. 2: Postoperative results after the lung resections.

\begin{tabular}{|c|c|c|c|c|c|c|c|}
\hline age & sex & Blood loss & H.drain & Cardiac complications & APV & Other & Hosp. \\
\hline & & $/ \mathbf{m l} /$ & /days/ & & /hrs/ & complications & /days/ \\
\hline 56 & male & 1550 & 4 & 0 & 0 & 0 & 12 \\
\hline 58 & female & 750 & 3 & atrial fibrilation & 6 & 0 & 14 \\
\hline 61 & male & 400 & 2 & atrial fibrilation & 0 & 0 & 9 \\
\hline 63 & female & 650 & 3 & 0 & 0 & 0 & 8 \\
\hline 63 & male & 850 & 3 & atrial fibrilation, failure & 120 & pno recid left & 24 \\
\hline 66 & male & 500 & 2 & 0 & 0 & 0 & 10 \\
\hline 66 & female & 950 & 3 & atrial flutter & 9 & 0 & 15 \\
\hline 69 & male & 500 & 2 & atrial fibrilation & 0 & 0 & 9 \\
\hline 70 & female & 600 & 2 & atrial flutter & 8 & bleeding & 16 \\
\hline 75 & male & 400 & 2 & 0 & 4 & bleeding /git// & 14 \\
\hline 78 & male & 450 & 2 & 0 & 0 & 0 & 11 \\
\hline Mean & $\mathbf{x x x x}$ & $\mathbf{6 9 0}$ & $\mathbf{2 , 5}$ & $\mathbf{x x x x x x x}$ & $\mathbf{1 3 , 4}$ & $\mathbf{x x x x x x x}$ & $\mathbf{1 2 , 9}$ \\
\hline
\end{tabular}

Legend: APV - artificial pulmonary ventilation

Tab. 3: Histological findings and TNM classification.

\begin{tabular}{|c|c|c|c|c|}
\hline age & histology & TNM & pTNM & Use of CPB \\
\hline 56 & Squamous cell Ca & T1N0M0 & T2N1M0 & On pump \\
\hline 58 & Carcinoid & T1N0M0 & T1N0M0 & On pump \\
\hline 61 & AdenoCa & T2N0M0 & T2N2M0 & On pump \\
\hline 63 & Squamous cell Ca & T1N0M0 & T1N0M0 & OAST \\
\hline 63 & AdenoCa & T2N0M0 & T2N0M0 & On pump \\
\hline 66 & Carcinoid & T1N0M0 & T1N0M0 & On pump \\
\hline 66 & Squamous cell Ca & T2N1M0 & T2N1M0 & Off pump \\
\hline 69 & Chondrohamartoma & Xxxxx & Xxxxx & On pump \\
\hline 70 & AdenoCa & T1N0M0 & T1N0M0 & On pump \\
\hline 75 & Non-spec. inflammation & Xxxxx & T2N1M0 & On \\
\hline 78 & AdenoCa & T2N2M0 & \\
\hline
\end{tabular}

Legend: on pump - using cardiopulmonary bypass; off pump - without using cardiopulmonary bypass; LAST - left anterior small thoracotomy 
In the second patient we discovered per operatively whilst taking the left mammary artery, a parietal structure, which was growing from the parietal pleura in the region of the $4^{\text {th }}$ rib. We took this structure away before the administration of heparin. The final histology proved a non-specific granulomatous inflammation.

The third patient in this group was a 63-year-old male with a serious mitral insufficiency classified as NYHA III. Simultaneously an opacity in the region of the $6^{\text {th }}$ segment of the right lower lobe was diagnosed. Histological verification using puncture biopsy was not done because of a high risk of possible iatrogenic pneumothorax due to his serious lung emphysema. A combined surgical approach was carried out using median sternotomy. Prior to heparinization we carried out a resection of the $6^{\text {th }}$ segment and then a standard replacement of the mitral valve using cardiopulmonary bypass followed. Histological examination proved to be primary adenocarcinoma without an involvement of the lymphatic nodes. The postoperative course was complicated by a left pneumothorax due to the previously mentioned lung emphysema.

The last patient from this group was a 66-year-old female, in whom we at first accomplished a resection of the $6^{\text {th }}$ segment from the right thoracotomy because of a mixed squamous cell and adenocarcinoma, which was verified by percutaneous biopsy. Using CPB a replacement of the mitral valve was undertaken because of a mitral defect.

All patients with a previous cardiac operation were cardiologically examined prior to the lung operation, but we did not perform a new coronarographic examination. The patients were transferred from an anti-aggregational treatment with salicylates to a low-molecular weight heparin, which was administered in a dosage $0,3 \mathrm{ml}$ to $0,8 \mathrm{ml} \mathrm{sub}$ cutaneously, according to the weight. We carried out the lung resections using short-term administration of antibiotics (ATB). Depending on the hourly blood loss during the postoperative period, we often transferred the patients to a low-molecular weight heparin in a dosage from $0,3 \mathrm{ml}$ to $0,6 \mathrm{ml}$ s.c., according to the weight, usually starting 6 hours after the operation.

In the patient after LAST, we proceeded to the administration of heparin only 12 hours after the end of the operation. In this case we had to perform the lung operation by extrapleural access because there were numerous concretions after the previous thoracotomy (LAST), and with respect to the run of the left mammary artery via the front mediastinum. That is why the blood loss through the pectoral drain were in hourly proportions during the first 3 hours $200 \mathrm{ml}$ each hour, followed by $100 \mathrm{ml}$, and reached $1400 \mathrm{ml}$ in total.

\section{Results}

There were no deaths in the whole patient group during the postoperative period and not even in the 30 days postoperatively. The postoperative course followed the standard norm with the loss of blood through the pectoral drain, in spite of the long-term pre-operational anti-aggregation therapy and early postoperative anti-aggregation therapy, ranging from $400 \mathrm{ml}$ to $1550 \mathrm{ml}$ (mean $690 \mathrm{ml}$ ). The need for keeping of the pectoral drainage using one drain with a lumen $32 \mathrm{~F}$ was 2-4 days. We did not notice any cardiac complications of a serious nature. In 3 patients, there arose newly formed tachyfibrilations of the atria on the first and second postoperative day after the revascularization and in one patient the quick fibrillation changed to the atrial flutter. Therefore an electric cardioversion was performed. Arrhythmic complications arose as a result of the surgery in the region of lung hilum rather than as a display of primary heart illness. After suitable cardiac therapy, and administration of amiodaron, a preoperative sinusoidal rhythm was preserved again. The length of artificial lung ventilation was dependent on the establishment of quality contact with patient following the general anaesthesia. It was not performed because of the breath insufficiency after the reduction of the lung tissue. The time of hospitalisation was in the range of 8 to 24 days (mean 13 days). Tab. 2 .

After discharge all patients are followed up at our cardiology department. The check-up at the pulmonary clinic is the same as with other patients, standard way in intervals of 3 months, 6 months, 1year and further according to the individual results. Patients from the second group, with proved tumorous growth in the catchment lymphatic nodes, were referred to the medical care of the Pulmonary clinic MF ChU a FH Hradec Králové, Pulmonary sanatorium Albertinum Žamberk, or oncological department according to their domicile.

We did not notice a relapse of cancer during the regular check-up in the following 5-year period. Two of the patients died, one of pulmonary complications after the radiation (from group 2), and one of the relapse of cardiac disease.

\section{Discussion}

Simultaneous affliction of lungs by a tumorous growth and the illness of the cardiovascular apparatus have among many different pathogens a common one, and it is indisputably smoking. In our group of $\mathbf{1 1}$ patients we found $\mathbf{8}$ (73\%) smokers of cigarettes. Cardiovascular and respiratory systems are pathophysiologicaly very intimately connected. The current medical practise is facing the problem, how to cure the combined affliction in the best and most effective way. It turned out that in patients with a non-small cell type of cancer stage I, II, and after the neoadjuvant chemotherapy even in stage III, surgical therapy is the most effective one, if the radical surgery is possible with respect to other associated diseases. The decision of the best approach is based on the staging of the tumorous growth in co-operation with the radiologists, using a method of TNM classification, 1977 version $(21,22)$. In the T1 group there were patients with a tumour of size up to $3 \mathrm{~cm}$, proliferating without afflicting the visceral pleura and without a bron- 
choscopic evidence of proliferation into the main or lobar bronchus. In the T2 group there are patients with the tumour bigger than $3 \mathrm{~cm}$, proliferating to visceral pleura, afflicting the main bronchus more than $2 \mathrm{~cm}$ from the carina, or causing atelectasis or an inflammation behind the tumour. We did not have any patients with stage T3 and T4, as it is a state unsolvable by radical surgery, when the tumour proliferates into the heart, mediastinum, oesophagus, vertebra etc. In our group the patients were classified to TNM according to the affliction of the nodes: in N0 group without a sign of affliction of catchment lymphatic nodes, $\mathrm{N} 1$ with an affliction of hilar ipsilateral and peribronchial nodes and N2 with an affliction of subcarinial and mediastinal ipsilateral nodes. These patients are primarily cured by neo-adjuvant chemotherapy prior to the lung operation, and after the restaging, if the tumour is reduced and mainly if the enlarged lymphatic nodes ease off, the patients are offered surgery. None of the patients was in the N3 group with affliction of contralateral nodes, and none was in M1 stage, which means the manifestation of a diagnosed metastatic affliction of other organs.

Similarly, it turns out that surgical therapy of the ischemic disease, in spite of the progress in medicamentous therapy and invasive radiological methods, is still the most effective one. In principal it is possible to cure the patients in three ways.

1. The most often and favoured method is a cardiac operation in the first period. A correct opinion that a serious heart disease can cause a fatal complication during the lung operation is of course still valid. This is definitely a safe and tried procedure but it is not easy to find the proper time to carry out the successive lung operation. It is also often hard to persuade the patients to undergo another serious operation in a short time after the first one. Another problem is the possibility of damaging the immune system of the patient with tumorous growth by cardiopulmonary bypass during the cardiac operation. From literature we know that by using cardiopulmonary bypass many of the parameters of the immune system are changed. After the cardiopulmonary bypass the chemotaxis of leucocytes is changed, the defence mechanism of the cells immunity, especially of the T-cells declines, the permeability of the cell membranes is changing, and the number of free oxygen radicals is rising up $(2,3,15,28)$. The decline of the immune stamina of the organism can participate in the support of the tumorous growth and accelerate the spread of the tumorous cells through the lymphatic system (1). The negative impact of the cardiopulmonary bypass on the immune system can be in some cases eliminated by accomplishing the cardiac operation without that (OPCAB, MIDCAB).

2. The second possibility is to perform the pulmonary resection knowing the high risk of cardiac complications in cases with a known cardiac disease, and carry out the cardiac operation subsequently. It is rather a theoretical approach, because firstly the surgeon would expose himself unnecessarily to the known risk of postoperative cardiac complications, and secondly before the pulmonary resection we never know whether the patient would need additional chemotherapy or radiotherapy after the pulmonary resection is done. Another necessary oncological treatment would disproportionately put the cardiac operation off. Certain possibility is in some cases provided by a hybrid procedure. At first we carry out a recanalization of closed coronary arteries using a non-invasive method PTCA, and subsequently a lung operation in the next period. This is definitely a method of choice in isolated stenoses of coronary stream, but most of our patients suffer from a diffusion affliction of coronary arteries. Another drawback of this approach is the necessity of a time interval from PTCA, at least 1-3 months, according to the type of stent, because of the necessary decisive anticoagulant and anti-aggregation treatment.

3. Considering the above mentioned reasons, some departments try to cover both of the systems together using the surgical therapy $(6,10,18)$.

The possibilities of surgical approach in combined disease of the heart and lungs are various. From the point of view of the patient's benefit, though definitely not the most convenient for the surgeon, the approach via the median sternotomy seems to be the best one $(1,4,5,26)$. The operational approach for accomplishing the pulmonary resection via the median sternotomy is facilitated by involving the device for the cardiopulmonary bypass. The manipulation with the stopped heart is then easier and the access to the pulmonary hilum is facilitated, but at the expense of disproportionally prolonged time of heart stoppage and total time of the cardiopulmonary bypass. We present this approach only to show an integral overview of operational possibilities. It can be used perhaps in exceptional cases, mostly in unexpected complications during the cardiac operation. We have had one sporadic experience with this approach in performing the Trendelenburg's operation of massive pulmonary embolism in the cardiopulmonary bypass. The lung parenchyma was devastated by bleeding and we were forced to use the cardiopulmonary bypass and carry out a left pneumonectomy. On the other hand a pulmonary resection through the median sternotomy is possible before the total heparinization and before starting of device for cardiopulmonary bypass, though it is definitely more difficult than the classical thoracotomic approach. Mainly accomplishing of the left lower lobectomy is very difficult especially in patients with cardiac disease, the consequence of which is often hypertrophy of the left heart ventricle. Another possibility is to perform during single anaesthesia a pulmonary resection from the respective posterolateral thoracotomy, and then continue the cardiac operation via the sternotomy, using the cardiopulmonary bypass or without it.

It does not seem to be profitable to carry out a parallel operation of heart and lungs using a combination of two 
different approaches (median sternotomy and posterolateral thoracotomy, or transverse thoracotomy with opening both pleural cavities), mainly because of more severe postoperative discomfort for the patient. Another possibility of a parallel operational approach is the use of LAST in isolated revascularizations of the anterior inter-ventricle branch (LAD), where it is possible to perform resections on the left lung wing only by widening the operational access from the anterolateral thoracotomy. The next possibility is to adjust the operational approach in revascularization of the myocardium without cardiopulmonary bypass (OPCAB) from the left thoracotomy with a need of simultaneous revascularization of coronary arteries in the range of LAD, $\mathrm{RD}, \mathrm{RMS}$, and the tumours of the left lung wing, or from the right thoracotomy in isolated affliction by $\mathrm{RC}$ and tumours of the right lung wing.

The advantages of the above mentioned operational approaches can be medical (we treat both diseases during single hospitalisation and single anaesthesia), as well as economical. Significant advantage is time factor, because waiting for the the second operation, after a needed convalescence, gives a chance to the continuing of tumorous growth and its proliferation. The psychological effect is certainly essential for the patients who know about the tumorous proliferation and are waiting for the therapy. Another medical advantage is the possibility to avoid the effects of the cardiopulmonary bypass on the organism suffering from oncological disease $(8,16,18,19)$. An indisputable advantage of median sternotomy is the possibility to perform bilateral mediastinal lymphadenectomy, which is important not only for the therapy, but for the prognosis. Considering current medical abilities the risk of combined operations is not high. The departments dealing with these problems in more detail do not refer higher mortality. Nor does the frequency of bleeding, respiratory and cardiac complications exceed the number of complications after isolated outputs (27).

In the literature, the attitude is controversial, mainly because the approach via the median sternotomy is technically more difficult. Another argument is the fact, that it is not possible to remove sufficiently all nodes especially from the region around the tracheal bifurcation. Next argument is the fact that the cardiac operation comes immediately after the lung operation without waiting for the results of the quick biopsy of the removed section. If the result of the histology is questionable and if it is necessary to widen the pulmonary resection, this may increase the risk of complications, when the patient is already on the cardiopulmonary bypass and fully heparinized (23).

According to the literature and our experience it seems to be profitable to try to perform a combined operation in patients with disease of both heart and lungs. If this procedure is not feasible, the solution can come from revascularization without using cardiopulmonary bypass (MIDCAB, $\mathrm{OPCAB}$ ) and performing the lung surgery in classical way in as short time as possible after convalescence. The lung operation can then be more complicated, because it is a re- operation usually in postoperative adhesions after the former extraction of mammary artery or after the opening of pleural cavities.

\section{Conclusion}

It is certainly not possible to make definite conclusions and general instructions for the procedure based on our relatively short term experience. Every case must be evaluated individually. It is necessary to find an optimal way of therapy in conjunction of cardiosurgery with the chest surgery. The retrospectively evaluated set of our patients is not particularly large. Published sets from institutions that deal with concurrent operations of heart and lungs more widely have not been too large as well. They usually encompass about 10 patients $(17,23,24)$. For the time being, in our department we don't routinely pursue combined anatomical resection planned lung outputs using median sternotomy. We usually perform wedge-shaped excisions of incidentally diagnosed benign deposits in lung parenchyma using this surgical access. Up to now we have operated on the patients with an ischemic heart disease and simultaneously known tumorous disease of lungs mainly using the cardiopulmonary bypass. With the development of revascularization operations without cardiopulmonary bypass we will definitely prefer this technique, unless a combined operation is possible.

\section{Literature}

1. Byrne J, Leatche M, Agnihotri A, Bueno R. The use of cardiopulmonary bypass during resection of locally advanced thoracic malignancies. Chest 2004;125:1581-6.

2. Chiba Y, Morioka R, Muraoka A, Ihaya T. Effects of depletion of leukocytes and platelets on cardiac dysfunction after cardiopulmonary bypass. Ann Thorac Surg 1998;65(1):107-13.

3. Colman RW. Platelet and neutrophil activation in cardiopulmonary bypass. Ann Thorac Surg 1990;49:32-4.

4. Conenery C, Knoentgen J, Anagnostopoulos C. Median sternotomy for pneumonectomy in patients with pulmonary complications of tuberculosis. Ann Thorac Surg 2003;75:1613-17.

5. Cooper JD, Nelems JM, Pearson FG. Extended indications for median sternotomy in patients requiring pulmonary resection. Ann Thorac Surg 1978;26:413-9.

6. Danton M, Anikin V, McManus KG, McGiuganJA, Campalani G. Simultaneous cardiac surgery with pulmonary resection: presentation of series and review of leterature. Europ J of Cardiothor Surg 1998;(13):667-72.

7. Doll R, Hill A.B. Smoking and carcinoma of the lung. BMJ, 1950; 221,739-48.

8. Dominick G, Leilani F, Madhu V, Wilson K. Neutrophil leukotrine generation increases after cardiopulmonary bypass. J Thorac Cardiovasc Surg 1994;108:642-7.

9. Dyszkiewicz W, Jemielity M, Piwkowski C, Perek B, Kasprzyk M. Simultaneous lung resection for cancer and myocardial revascularization without cardiopulmonary bypass (off-pump coronary artery bypass grafting). Ann Thorac Surg 2004; $77: 1023-7$

10. Dominick G, Leilani F, Madhu V, Wilson K. Neutrophil leukotrine generation increases after cardiopulmonary bypass. J Thorac Cardiovasc Surg 1994;108:642-7.

11. Elami A, Korach A, Rudis E. Lung cancer resection or aortic graft replacement with simultaneous myocardial revascularization without cardiopulmonary bypass. Chest 2001;119:1941-3.

12. Fingerland A. Příspěvek ke studiu vlivu kouření cigaret na nálezy v pitevním materiálu. Suppl sbor věd Prací LF UK Hradec Králové 1973;16(2):137-54.

13. Graham EA, Singer I. Succesfull removal of an entire lung for carcinoma of the bronchus. J Amer Med ass 1993;1001:1371-3.

14. Hiatt HH. Origins of human cancer. Book C: Human risk assesement. Cold Spring Harbor Conferences on Cell Protection. Cold Spring Harbor Laboratory 1977. 
15. Chiba Y, Morioka R, Muraoka A, Ihaya T. Effects of depletion of leukocytes and platelets on cardiac dysfunction after cardiopulmonary bypass. Ann Thorac Surg 1998;65(1): 107-113.

16. Ilton M, Langton E, Taylor N, Misso M. Differential expression of neutrophil adhesion molecules during coronary artery surgery with cardiopulmonary bypass. J Thorac Cardiovasc Surg 1999;118(5):930-7.

17. Jensen RH, Storgaard M, Vedesldal R, Obel N. Imparied neutrophil chemotaxis after cardiac surgery. Scand J Thorac Cardiovasc Surg 1995;29:115-8.

18. Koksal C, Sarikaya S, Zengin M, Atasalihi A. Combined off-pump coronary revascularization and lung resection. Acta Med (Hradec Králové) 2002;45(3):119-21.

19. Knudsen F, Anderson L. Biological aspects of cardiopulmonary bypass. J Cardiothorac Anesth 1990;4:245-58.

20. Lonsky V. Mimotělní oběh v klinické praxi. Grada Publishing a.s.,2004;94-100.

21. Magrath EA, Litvak J. Cancer in developing countries: opportunity and challenge. J Natl Cancer Inst 1993;85:862-8.

22. Mountain CF, Carr DT, Anderson WAD. A systém for the clinical staging of lung cancer. AJR 1974;120:130-5.
23. Mountain CF. Revisions in the international systém for staging lung cancer. Chest 1997;111:1710-21.

24. Patane F, Verzini A, Zingarelli E, Summa M. Simultaneous operation for cardiac disease and lung cancer. Interactice Cardiovasc Thor Surg 2002;(1):69-71.

25. Rao V, Thomas RJ, Wiesel RD, Komeda M, Cohen G, Ikonomidis JS, Christakis GT. Results of combined pulmonary resection and cardiac operation. Ann Thorac Surg 1996;(62):342-6.

26. Šimek J, Rešl M, Žáček P, Štětina M, Habal P. Chirurgická léčba plicní rakoviny. Acta Med (Hradec Králové) Suppl. 2001;44:65-75.

27. Ulicny KS Jr, Schmelzer V, Flege JB Jr, Todd JC, Mitts DL, Melvin DB, Wright CB. Concomitant cardiac and pulmonary operation:the role of cardiopulmonary bypass. Ann of Thor Surg 1992;(54):289-95.

28. Urschel HC, Razzuk MA. Median sternotomy as a standard approach for pulmonary resection. Ann off Thor Surg 1986;(41):130-4.

29. Utoh J, Yamamoto T, Miyauchi Y. Is an increased leukotrine-generating capacity a specific phenomenon for cardiopulmonary bypass? J Thorac Cardiovasc Surg 1995;110(1):276

Submitted May 2006. Accepted September 2006

MUDr. Petr Habal, University Hospital in Hradec Králové, Department of Cardiosurgery, Sokolská 581, 50005 Hradec Králové, e-mail:phabal@seznam.cz 